\title{
El jeroglífico del sentimiento: la poesía amorosa de Sor Juana
}

(C) Margo Glantz

Facultad de Filosofía y Letras of the Universidad Nacional Autónoma de México

\section{E-mail-amatista@servidor.unam.mx}

Las bajas ficciones de la retórica

Ved es creer que, las causas

con efectos desconformes,

nieves el fuego congele,

que la nieve llamas brote...

¿Cómo el corazón podrá,

como sabrá el labio torpe

fingir halago, olvidando;

mentir, amando, rigores?

¿Cómo sufrir abatido

entre tan bajas ficciones,

que lo desmienta la boca

podrá un corazón tan noble?

¿Y cómo podrá la boca, cuando el corazón se enoje, fingir cariños, faltando quien le ministre razones?

¿Podrá mi noble altivez consentir que mis acciones de nieve y de fuego, sirvan de ser fábula del orbe?... $¡$ Oh vil arte, cuyas reglas tanto a la razón se oponen, que para que se ejecuten es menester que se ignoren!

Si tomamos al pie de la letra los versos de Sor Juana que he citado a manera de epígrafe, correspondientes al conocido Romance que empieza "Supuesto, discurso mío, que gozáis en todo el orbe...", intitulado así por sus editores españoles: "Que resuelve con ingenuidad sobre problema entre las instancias de la obligación y el afecto" (Méndez Plancarte, 18-19), y catalogado por Méndez Plancarte con el número 4, en el primer tomo de las Obras completas, se advierte una asociación, una correspondencia reiterada entre dos órganos del cuerpo. Uno interior e invisible, el corazón, centro de la vida, el afecto y lo verdadero, en consecuencia noble, y otro órgano 
exterior y visible, la boca, desde donde fluye la voz, se emiten las palabras, se exhalan los suspiros y pueden deleitarse los sentidos. Esa correlación se produce de manera paradójica: la palabra, en apariencia fiel reflejo del sentimiento, lo traiciona y al hacerlo desvirtúa la razón. En ese transcurso impalpable que hace visibles--o mejor, audibles--Ios movimientos del corazón, los sentimientos se falsean y se convierten en engaño, un engaño retórico. ¿Es imposible expresar la pasión? ¿Cómo destruir la barrera que el mismo cuerpo impone? Y, sobre todo, ¿cómo romper la cárcel de la retórica y de la cortesanía que en última instancia estarían irremisiblemente ligadas?

Dámaso Alonso analiza algunos sonetos de Quevedo y los mecanismos por él utilizados para expresar esa "descarga afectiva" que permite que sus poemas puedan clasificarse entre los más grandes poemas de amor escritos en castellano:

Uno de los procedimientos más repetidos en la estructuración poética consiste en desarrollar a lo largo de una breve composición una imagen, muchas veces tomada del mundo de la naturaleza, y al final hacer brevemente una comparación con el estado psicológico de la persona que habla ... El procedimiento es, pues, trivial. Y no podemos atribuir originalidad ninguna técnica a Quevedo ... Sin embargo, su extraordinaria capacidad afectiva hace que el final sea apretado, estallante de lágrimas, auténtico dolor de hombre... (Alonso 561-62).

Se parte de una trivialidad, las imágenes convertidas en tópico y reiteradas siglo tras siglo, poeta tras poeta, bajo el imperio de la retórica, esa tirana que reinó desde el siglo $\mathrm{V}$ (A.C.) hasta el siglo XIX (Barthes 1974, 9-15). Partiendo de ese contrasentido, de la asociación de palabras banales, manoseadas, se puede aspirar a crear un poema perfecto, operación, hay que convenir, muy parecida al oxímoron fuego-nieve denunciado por Sor Juana en su romance. Pero vuelvo a plantear las preguntas: ¿Cómo salir del círculo vicioso trazado por la tradición, la retórica, el decoro cortesano y la dificultad de inventar un nuevo lenguaje amoroso? ¿Cómo trascender los límites del lenguaje para expresar lo inexpresable? Desenredar ese jeroglífico en algunos poemas de Sor Juana será quizá la imposible tarea de este ensayo.

\section{El corazón, un jeroglífico de variado plumaje}

El corazón es el centro de la vida, "reloj humano", lo llama Sor Juana

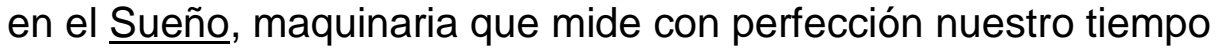


corporal: "vital volante que, si no con mano,/ con arterial concierto, unas pequeñas / muestras, pulsando, manifiesta lento/ de su bien regulado movimiento" (Méndez Plancarte, v. I, 340). El corazón puede entonces concebirse de muy diversas formas, ya sea como una máquina (Sabat de Rivers 1998, 355-83) que rige nuestra fisiología, es decir, como parte de un mecanismo corporal que nos mantiene vivos y es objeto susceptible de estudio científico y técnico. Es importante subrayar que los descubrimientos de Harvey en el siglo XVII sobre la circulación de la sangre probaron fisiológicamente los caminos que seguía el flujo vital y, Descartes, en su Tratado de las pasiones del alma, reconocía las relaciones recíprocas que existen entre el corazón y el cerebro y pensaba que ciertas pasiones podían producir alteraciones en la sangre, datos que probablemente no conocía Sor Juana, pero que de cualquier manera fueron manejados en su tiempo.

Asimismo, el corazón está asociado a un simbolismo particular que abarca distintos tipos de discursos y que en la segunda mitad del siglo XVII dio origen a una devoción que eligió al Sagrado Corazón de Jesús para otorgarle nuevos significados a antiguos símbolos religiosos--exaltando de manera particular la corporeidad y en consecuencia la humanidad de Cristo--, símbolos que dan cuenta de una coexistencia de discursos paralelos dentro de la ciencia y la religión que incidieron uno sobre el otro, como bien lo prueba Leonor Correa (104-105).

Pero en la literatura amorosa el corazón es antes que nada el órgano del sentimiento y del deseo. Flaubert pensaba que al hablar del corazón las mujeres designaban en realidad otras partes del cuerpo y Roland Barthes, afirma en sus Fragmentos del discurso amoroso:

CORAZON: Esta palabra vale para todo tipo de movimientos y de deseos, pero lo constante es que el corazón se constituya en objeto de donación--ya sea mal apreciado o rechazado.

El corazón es el órgano del deseo (el corazón se hincha, desfallece, etc., como el sexo), tal y como se le maneja, aprisionado, en el campo de lo Imaginario. ¿Qué es el mundo, qué es lo que el otro hará de mi deseo? Esa es la inquietud a donde convergen todos los movimientos del corazón, todos los 'problemas' del corazón (Barthes 1978, 52).

Entendido así, el corazón se constituiría como sinécdoque, la figura que toma la parte por el todo, localizando en un solo lugar de la 
corporeidad el deseo y permitiendo que la materialidad del cuerpo se destruya a golpes de retórica [1]. El corazón regula el cuerpo pero a su vez éste, el cuerpo, funciona a manera de resguardo y de cárcel del corazón: el pecho se convierte en una fortaleza o más bien en una vestimenta protectora para que el sentimiento no se desborde. Por ello Sor Juana--y otros poetas antes que ella--configura en ciertos poemas un arsenal de imágenes de guerra donde la carne sufre una metamorfosis y acaba convirtiéndose en materia mineral para poder pertrecharse mejor contra el acoso amoroso, no siempre con éxito, como en el sexto verso del soneto de los clasificados por Méndez Plancarte como de amor y discreción: "yo templaré mi corazón de suerte/ que la mitad se incline a aborrecerte/ aunque la otra mitad se incline a amarte..." (v. 1, 293) Es decir, el corazón templado como el acero se vuelve objeto de atracción magnética, como en el segundo cuarteto del soneto 165: "Si al imán de tus gracias, atractivo..." Más significativo en este sentido es el romance catalogado con el número 7 por Méndez Plancarte:

Allá va Julio de Enero, ese papel, no a tus manos al alma sí, que si es nieve será de mis tiros blanco. Arma de loriga el pecho, anima aliento bizarro, y a puntas de mis desdenes marmóreos prevén reparos. Dilata del corazón los senos más reservados, y en inútiles defensas dobla a mi valor el lauro. Arma el alma de cordura de sufrimiento el cuidado, de reflejas lo atrevido y de prudencia lo vano. Que no bastará a librarte de mi desdén irritado, ni las defensas del pecho ni los esfuerzos del brazo, pues llevo para rendirte, por ministros del estrago, enojo que brota furias, desdén que graniza rayos... (Méndez Plancarte, v. I, 2627)

Imágenes muy semejantes, por lo demás, a las que la monja utilizó en la Loa de El Divino Narciso justo cuando los españoles usan sus 
armas para convencer a los infieles de que la mejor religión es la católica (esos mismos naturales de la antigua Tenochtitlán quienes minutos antes habían abierto los pechos de sus víctimas para ofrendarle su corazón al Gran Dios de las Semillas). Sería interesante remachar el paralelismo y traer a colación aquí la imagen de un corazón disecado, el de Fernández de Santa Cruz, arrancado del tórax del obispo para ofrecerse como recuerdo amoroso a las monjas del convento de Santa Mónica, un corazón-reliquia, objeto de un sermón obituario de Fray Ignacio de Torres, analizado por María Dolores Bravo en su ensayo "La permanencia del corazón". En ese texto los conocimientos anatómicos servirán para construir una alegoría de la trascendencia, en donde el corazón de Santa Cruz custodiado cuando aún estaba vivo "por la membrana del pericardio y el muro de las costillas"... "que en vida son sepulcro de un corazón vivo, sean en muerte sepulcro de un corazón muerto" (Bravo 95).

\section{El corazón deshecho entre tus manos}

Si sólo el corazón es verdadero y si la palabra es mentirosa, ¿qué puede hacer el amante para que el amado reconozca la autenticidad de la pasión? Ya señalaba antes cómo el pecho se maneja como si fuese una armadura para proteger el corazón y evitar que se rompa. También mencioné la correlación que Sor Juana establece entre el corazón y la boca, correlación fallida puesto que termina en un engaño retórico, como palabra mentirosa. De esta oposición metafórica se deduce una exigencia, la de contar con otros elementos corporales sustitutivos que puedan revelar lo inefable, efectuar algo así como una radiografía amorosa del corazón. Un desplazamiento metonímico se produce y los ojos sustituyen a la boca: oímos literalmente con los ojos: "Oye la elocuencia muda/ que hay en mi dolor, sirviendo/.... las lágrimas, de conceptos" , en el Romance 6 (Méndez Plancarte, v. I, 24). Así, un término, el corazón, se revela en otros términos manejados como los estados diversos de una misma identidad, desarrollados a manera de distintos momentos de la misma historia. Dice el muy conocido soneto clasificado como el número 164:

En que satisface un recelo con la retórica del llanto

Esta tarde, mi bien, cuando te hablaba, como en tu rostro y tus acciones vía que con palabras no te persuadía, que el corazón me vieses deseaba; y Amor, que mis intentos ayudaba, venció lo que imposible parecía, pues entre el llanto, que el dolor vertía, el corazón deshecho destilaba. 
Baste ya de rigores, mi bien, baste; no te atormenten más celos tiranos, ni el vil recelo tu quietud contraste con sombras necias, con indicios vanos, pues ya en líquido humor viste y tocaste mi corazón deshecho entre tus manos.

La limpidez del lenguaje con que está escrito el soneto concuerda con la calidad de las lágrimas--en la tradición poética identificadas con la transparencia--es más: esa impenetrable coraza que separa al órgano interior, oculto dentro del tórax, cubierto por los músculos y la piel, puede destruirse gracias a la fuerza del amor que opera a la manera de una transmutación alquímica cuyo resultado sería ese precipitado amoroso, el "líquido humor" que en virtud de la exaltación de la pasión es la prueba fehaciente aunque metafórica de un "corazón" fiel y amante. El líquido humor hace posible en el soneto la transición entre lo invisible y lo visible: los sentimientos que aparentemente sólo pueden expresarse mediante palabras y ciertos actos concretos-cariños o regalos--, pálidos reflejos de su veracidad, se concretizan en el llanto derramado por el amante en las manos de su amado, prueba irrefutable del sentimiento expresado que sanciona su verdad, más allá de las palabras que lo evocan. Y aquí entramos en una delicada connivencia entre el lector y el poeta: la expresión del amor se verbaliza según las reglas que impone la tradición poética--cárcel verbal, cárcel formal--y suele ordenarse siguiendo una serie de imágenes codificadas y reglas de versificación que en algunos poetas es un mecánico ejercicio técnico. ¿Un vulgar calentamiento de la sangre, sencilla operación química, reiteraría el milagro del amor correspondido? Examinemos otro soneto donde el corazón trabaja para construir una máquina productora de sentimientos visibles y convalidar las palabras (Soneto 177):

Discurre inevitable el llanto a vista de quien ama

Mandas, Anarda, que sin llanto asista a ver tus ojos, de lo cual sospecho que el ignorar la causa es quien te ha hecho querer que emprenda yo tanta conquista.

Amor, señora, sin que me resista, que tiene en fuego el corazón deshecho, como hace hervir la sangre allá en el pecho, vaporiza en ardores por la vista.

Buscan luego mis ojos tu presencia que centro juzgan de su dulce encanto, y cuando mi atención te reverencia, los visüales rayos, entretanto, 
como hallan en tu nieve resistencia, lo que salió vapor, se vuelve llanto.

En este soneto la monja juega con un equívoco: utiliza una voz masculina (la del amante que se dirige a su amada), y cumple con un ejercicio retórico (el del poeta que puede hablar en abstracto sin que se advierta su sexo)-"mi cuerpo", dice la monja en un romance, "es neutro o abstracto, cuanto/ sólo al alma deposite". Se trata de un ejercicio que reitera la escasez de voces femeninas en la poesía de su tiempo, a la vez que demuestra su habilidad para asumir todas las voces y hacerlas verosímiles.

Sor Juana echa mano en este soneto, como lo haría en Primero

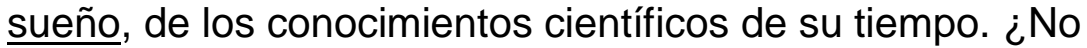
concordaría con Descartes a quien probablemente no conoció, pero con el que coincide en que "ciertas modificaciones en la sangre llevaban al nacimiento de pasiones como la alegría o la desesperación, y a la vez, las ideas surgidas en nuestra imaginación, a través de los nervios causaban una rarificación de la sangre, la cual enviaba al cerebro espíritus que fortalecían algún sentimiento" (Correa, 108)? Aunque Descartes se refería en este caso al miedo, incluye también los mecanismos fisiológicos que al influjo de la pasión "calientan" la sangre y producen "una especie de efervescencia que la empujaba a salir del corazón". (Ibid.). Eso es literalmente lo que sucede en el poema: el fuego producido por la pena amorosa "deshace" el órgano de la vida--"el corazón deshecho"--y ese sentimiento extremo "hace hervir la sangre", expresión por otra parte muy corriente en el lenguaje coloquial: el calor así provocado efectúa una combustión, cual caldero puesto al fuego cuya agua al hervir se evaporara gracias al proceso de calentamiento, logrando un efecto poético: la trasmutación de las palabras hace que la sangre se destile y "vaporiza en ardores por la vista".

\section{El ensangrentado noble pecho}

Por obra y gracia de la metáfora, el corazón parece destilarse como los licores, pero el pecho sigue manteniendo su coraza, las lágrimas son apenas la expresión, el trasunto, de la pasión correspondida. Una fórmula única existe para romper el corazón, metafóricamente hecho pedazos por la pasión o convertido en líquido transparente para servirle de espejo. Esa posibilidad podría formularse utilizando unas palabras de Roland Barthes, en relación a "Tácito y el barroco fúnebres". Ciertas maneras de morir "hace(n)r de la muerte un líquido, es decir, la convierten en duración y en purificación" (Barthes 1972, 102). Eso es lo que sucede en unos sonetos de Sor Juana agrupados por Méndez Plancarte como sonetos histórico-mitológicos y 
trabajados minuciosamente por Georgina Sabat [2] En el catalogado como 153 se nos describe la muerte de Lucrecia, quien prefiere suicidarse antes que dejarse violar por un monarca romano: " $\mathrm{iOh}$ famosa Lucrecia, gentil dama,/ de cuyo ensangrentado noble pecho/ salió la sangre que extinguió, a despecho/ del rey injusto, la lasciva llama!" (Méndez Plancarte, v. I, 281). Cuando el tórax es atravesado de verdad, cuando esa caja fuerte que resguarda se abre con violencia el corazón se rompe y viene la muerte. Aquí parecería que hemos accedido al reino de lo real. Sor Juana dedica otro soneto a Lucrecia, el 154, en donde su honestidad es causa a la vez de su muerte y de su fama y la obstinación amorosa de Tarquino se maneja como metáfora de un mito, el de Sísifo, pero no se hace ninguna alusión al pecho destrozado de Lucrecia. Por el contrario, es en el último soneto de la serie, el que narra la muerte de Píramo y Tisbe, en que ambos se dan la muerte con la misma espada. Parecería de primera instancia que en el soneto la historia se minimiza cuando la voz poética anuncia blandamente: "Píramo amante abrió la vena/ del corazón...", pero se nos advierte la desmesura del doble suicidio desde el epígrafe y se refuerza con las imágenes: la sangre que sale a borbotones de los dos pechos destrozados altera la naturaleza: el moral pierde su blancura y adquiere un color de sangre coagulada, "de un funesto moral la negra sombra", y esa misma doble sangre derramada trastorna "la verde matizada alfombra". La muerte organiza en este soneto la forma más violenta de la correspondencia amorosa, la de dos pechos enlazados por la sangre.

Se resuelven así las dos cadenas metafóricas: la del corazón y las lágrimas y la del corazón y la sangre, dos formas de producción de lo húmedo, dos formas de deshacer al corazón, las dos únicas que pueden destruir la prisión, ese cerco de huesos y de carne que protege al corazón. Aprisionada a su vez por el marco poético escogido, que por lo menos desde Petrarca parecía ser el más idóneo para expresar la pasión amorosa, la monja novohispana, como antes otros poetas--Lope, Góngora, Quevedo--pudo trascender la cárcel de la retórica y quizá la del claustro, aunque en otra parte haya dicho: "poco importa burlar brazos y pecho/ si te labra prisión su fantasía". Me permitiré, para terminar una fantasía, esbozar una relación entre ese órgano imprescindible para el jeroglífico de los sentimientos-- ¿la fisiología del amor?--y la forma del soneto. Como el corazón, el soneto se cierra sobre sí mismo, jamás puede salirse de su marco-así se trate del vapor que la pasión hace asomar a los ojos. A pesar de sus extremos y de la combustión que transforma los elementos y los convierte en otra cosa mediante una mezquina combinación térmica, la forma del soneto es muy semejante a la del corazón, este 
delicado instrumento cerrado sobre sí mismo que cuando se desborda ocasiona la muerte del cuerpo y también la del poema.

\section{Notas}

1 Raúl Dorra, "Jacinto Polo, maestro de Sor Juana," en Margo Glantz, ed. Sor Juana Inés de la Cruz y sus contemporáneos, México, UNAM, 1998, p.126.

2 Georgina Sabat de Rivers, "Heroínas de amor trágico en cinco sonetos de Sor Juana" en En busca de Sor Juana, México, UNAM, 1998, pp.153-173.

\section{Obras citadas}

Alonso, Dámaso. Poesía española. Madrid: Gredos, 1962.

Barthes, Roland. "Tácito y el barroco fúnebre." En Ensayos críticos. Barcelona: Seix Barral, 1967,132.

---. La antigua retórica. Trad. Beatriz Dorriots. Buenos Aires: Edición Tiempo Contemporáneo, 1974.

---. Fragments du discours amoureux. Paris: Seuil, 1977. 63.

Bravo, María Dolores. "La permanencia del corazón." En La excepción y la regla. México: UNAM, 1998. 91-99.

Correa, Leonor. "El corazón. Dos representaciones en los mundos científico y religioso del siglo XVII." Historia y Grafía. México: Universidad lberoamericana, 1997, núm. 9, pp. 90-122.

Cruz, Sor Juana Inés de la. Obras completas. Ed. Alfonso Méndez Plancarte. México: Fondo de Cultura Económica, 1951.

Dorra, Raúl. "Jacinto Polo, maestro de Sor Juana." En Sor Juana Inés de la Cruz y sus contemporáneos. Ed. Margo Glantz. México: UNAM, 1998. 123-137.

Glantz, Margo. Mi corazón deshecho entre tus manos: Sor Juana: sonetos de amor y discreción, inédito.

Molho, Mauricio. Semántica y poética (Góngora, Quevedo). Barcelona: Editorial Crítica, 1977. 
Paz, Octavio. Las trampas de la fe. México: Fondo de Cultura Económica, 1982.

Sabat de Rivers, Georgina. "Veintiún sonetos de Sor Juana y su causística del amor." En Sor Juana y su mundo. Comp. Sara Poot Herrera. México: Universidad del Claustro de Sor Juana, Fondo de Cultura Económica, et al. 1995. 397-445.

---. "Heroínas de amor trágico en cinco sonetos de Sor Juana." En En busca de Sor Juana . México: UNAM, 1998.153-173.

---. "Imágenes técnicas y mecánicas en la poesía de Sor Juana." En Sor Juana Inés de la Cruz y sus contemporáneos. Ed. Margo Glantz. México: UNAM, 1998. 335- 356.

---. En busca de Sor Juana. México: UNAM, 1998. 355-383. 